CORRECTION

\title{
Correction to: Nationwide randomised trial evaluating elective neck dissection for early stage oral cancer (SEND study) with meta-analysis and concurrent real-world cohort
}

Iain L. Hutchison, Fran Ridout, Sharon M. Y. Cheung, Neil Shah, Peter Hardee, Christian Surwald, Janavikulam Thiruchelvam, Leo Cheng, Tim K. Mellor, Peter A. Brennan, Andrew J. Baldwin, Richard J. Shaw, Wayne Halfpenny, Martin Danford, Simon Whitley, Graham Smith, Malcolm W. Bailey, Bob Woodwards, Manu Patel, Joseph McManners, Chi-Hwa Chan, Andrew Burns, Prav Praveen, Andrew C. Camilleri, Chris Avery, Graham Putnam, Keith Jones, Keith Webster, William P. Smith, Colin Edge, lain McVicar, Nick Grew, Stuart Hislop, Nicholas Kalavrezos, lan C. Martin and Allan Hackshaw

(c) The Author(s) 2021

British Journal of Cancer (2022) 126:831; https://doi.org/10.1038/s41416-021-01678-2

Correction to: British Journal of Cancer 121:827-836, https://doi.org/ 10.1038/s41416-019-0587-2, published online 15 October 2019

The original version of this article unfortunately contained a mistake. A correction is needed for one of the trials in the metaanalysis (Fig. 3). For Fakih et al. 1989, the relative risk of death (used as an estimate of the overall survival hazard ratio; as the authors did with other trials that did not report hazard ratios directly) was calculated using 8 deaths among 30 patients who had neck dissection versus 16 deaths among 40 patients who had resection only $(R R=0.67)$. The authors have since noted that there were 9 deaths among the 30 patients, yielding $\mathrm{RR}=0.7595 \% \mathrm{Cl}$ : $0.39-1.46$. This trial had a small weight in the meta-analysis, so the corrected pooled hazard ratio across all 5 trials is now $\mathrm{RR}=0.70$ (95\% Cl: 0.55-0.88); almost the same as that published $\mathrm{RR}=0.69$ (95\% Cl: 0.55-0.87). Nevertheless, the main focus should be on the authors SEND trial and D'Cruz et al. 2015, as they were the most contemporary and highest quality.
Open Access This article is licensed under a Creative Commons Attribution 4.0 International License, which permits use, sharing, adaptation, distribution and reproduction in any medium or format, as long as you give appropriate credit to the original author(s) and the source, provide a link to the Creative Commons license, and indicate if changes were made. The images or other third party material in this article are included in the article's Creative Commons license, unless indicated otherwise in a credit line to the material. If material is not included in the article's Creative Commons license and your intended use is not permitted by statutory regulation or exceeds the permitted use, you will need to obtain permission directly from the copyright holder. To view a copy of this license, visit http://creativecommons. org/licenses/by/4.0/.

(c) The Author(s) 2021 